\title{
Effect of the hardener to epoxy monomer ratio on the water absorption behavior of the DGEBA/TETA epoxy system
}

\author{
Ayrton Alef Castanheira Pereira ${ }^{1 *}$ and José Roberto Moraes d'Almeida ${ }^{1,2}$ \\ ${ }^{1}$ Mechanical Engineering Department, Universidade do Estado do Rio de Janeiro - UERJ, \\ Rio de Janeiro, RJ, Brazil \\ ${ }^{2}$ Chemical and Materials Engineering Department, Pontifícia Universidade Católica do \\ Rio de Janeiro - PUC-RJ, Rio de Janeiro, RJ, Brazil \\ *pereira.ayrton@gmail.com
}

\begin{abstract}
The water absorption behavior of the DGEBA/TETA epoxy system was evaluated as a function of the epoxy monomer to amine hardener ratio. Weight gain versus immersion time curves were obtained and the experimental points were fitted using Fickian and Non-Fickian diffusion models. The results obtained showed that for all epoxy monomer to hardener ratios analyzed water diffusion followed non-Fickian behavior. It was possible to correlate the water absorption behavior to the macromolecular structure developed when the epoxy/ hardener ratio was varied. All epoxy/hardener ratios present a two-phase macromolecular structure, composed of regions with high crosslink density and regions with lower crosslinking. Epoxy rich systems have a more open macromolecular structure with a lower fraction of the dense phase than the amine rich systems, which present a more compact two-phase structure.
\end{abstract}

Keywords: water absorption, epoxy resins, hardener to epoxy monomer ratio.

\section{Introduction}

Epoxy resins show high reactivity with many different chemical compounds, like aliphatic and aromatic amines, anhydrides and polyamides ${ }^{[1]}$. This characteristic is due to the presence of the very strained ethoxyline ring structure $^{[1,2]}$. Therefore, given a specific epoxy monomer, the mechanical properties of the epoxy system can be varied over fairly high bounds by changing the curing agent. Therefore, the observed variations on properties reflect differences on the macromolecular network developed. Besides the chemical nature of the hardener, other variables like the time and temperature of cure ${ }^{[3,4]}$ and the hardener to epoxy monomer ratio ${ }^{[5]}$ could produce very different macromolecular structures. For the epoxy system formed by the difunctional epoxy monomer, diglycidyl ether of bisphenol-A (DGEBA), and the hexafunctional aliphatic amine, triethylenetetramine (TETA), the hardener to epoxy ratio was shown to strongly affect mechanical ${ }^{[6,7]}$ and thermal properties ${ }^{[8]}$.

However, non-stoichiometric hardener/epoxy ratios could produce unstable macromolecular networks that could age more readily, due to temperature changes or even moisture absorption. The modifications induced by both temperature and/or moisture are directly linked to the presence of unreacted sites, maintained latent during the gelation and setting of the resin. Moisture absorption, in particular, could also promote undesirable dimensional changes on finished parts. It has to be noted that even for a completely cured epoxy system, many hydrophilic sites could be present on the final network developed. In fact, for this epoxy system the cure reactions scenarios are leaded by the primary amino addition reaction, occurring between primary amines $\left(-\mathrm{NH}_{2}\right)$ and the epoxy group, resulting on hydrophilic hydroxyl groups $(-\mathrm{OH})^{[1]}$.

For non-stoichiometric formulations with excess of epoxy monomer the epoxy rings could, in principle react with these hydroxyls groups forming ether groups ${ }^{[1,4]}$. But this secondary reaction will not contribute to reduce the number of hydrophilic $\mathrm{OH}$ groups and its effect is very restricted for reactions taking place below $150{ }^{\circ} \mathrm{C}^{[9]}$. Besides, amines are also strongly hydrophilic groups, and when in excess could contribute to moisture up-take and to resin plasticization ${ }^{[10]}$.

Earlier studies on the DGEBA/TETA system showed that the degree of cure, and therefore the presence of latent unreacted sites, is greatly affected by the hardener to epoxy ratio and that, for room temperature cured resins without post-curing, the consume of epoxy rings go to completion only for off-stoichiometric hardener rich mixtures ${ }^{[7]}$. Also, thermo-gravimetric analysis showed that some off-stoichiometric mixtures could have a two phase like microstructure, where very crosslinked domains could be embedded on a less crosslinked matrix ${ }^{[8]}$. These structural characteristics can strongly affect the moisture up-take behavior and contribute to a faster decrease of the mechanical performance of the material.

Therefore, in this work, the water absorption behavior of the DGEBA/TETA epoxy system was studied as a function of the hardener to epoxy ratio. Besides the stoichiometric formulation, epoxy rich as well as hardener rich mixtures were analyzed. The results obtained were correlated with former proposed networks developed due to the change on the hardener/epoxy ratio $^{[8]}$, and with the presence of unreacted sites. 


\section{Theoretical Background}

\subsection{Fickian behavior}

Several models are used to describe diffusion on polymers. The most common one uses the theoretical background of the 2 nd Fick equation, namely ${ }^{[11]}$

$$
\frac{\partial c}{\partial t}=\frac{\partial}{\partial x}\left(D \frac{\partial c}{\partial x}\right)
$$

In Equation $1 c$ is the water concentration at time $t, D$ the diffusion coefficient and $x$ the space coordinate measured normal to the cross section. For infinity large plates of thickness $h$ and considering that diffusion occurs only perpendicularly to the specimens' thickness, the solution of Equation 1 is given by ${ }^{[11]}$ :

$$
\frac{M_{\%}}{M_{\infty}}=1-\frac{8}{\pi^{2}} \sum_{j=0}^{\infty} \frac{\exp \left[-(2 j+1)^{2} \pi\left(\frac{D t}{h^{2}}\right)\right]}{(2 j+1)^{2}}
$$

where $M_{\%}$ is the mass of water absorbed at a time $t$, and $M_{\infty}$ is the mass absorbed at saturation. Equation 2 converges fast as $t$ increases, and, therefore, one can use the first term of the series as a good approximation. An analytical simplification of Equation 2 for values of $M_{o} / M_{\infty}>0.5$ is given by ${ }^{[12]}$.

$$
\frac{M_{\%}}{M_{\infty}}=1-\exp \left[-7.3\left(\frac{D_{x} t}{S^{2}}\right)^{0.75}\right]
$$

where $S=h$ if both sides of the test specimen are exposed to the absorption medium and $S=2 h$ if only one side is exposed. For short times of exposure, when $M_{\%} / M_{\infty}<0.5$ Equation 2 can be approximated by ${ }^{[12]}$ :

$$
\frac{M_{\%}}{M_{\infty}}=\frac{4}{h} \sqrt{\frac{D t}{\pi}}
$$

A general equation based on the same approach of the Fick law but covering the entire range of absorption was proposed by McKague et al. ${ }^{[13]}$, namely:

$$
\frac{M_{\%}}{M_{\infty}}=\tanh \left(\frac{4}{h} \sqrt{\frac{D t}{\pi}}\right)
$$

\subsection{Non-fickian behavior}

Several authors consider that the Fickian model is not able to describe the complete water absorption behavior of several polymers and/or polymer composites ${ }^{[14-17]}$. In fact, in many instances it was found that the Fickian behavior can fit the experimental data points only at the early stages of the absorption process, failing, however, to describe the behavior when the absorption time increases.

Other models have appeared to overcome the inadequacy of the Fickian model to describe the experimental behavior of certain polymers and polymer composites models. These models take new assumptions such as water molecules acting both as a bound and unbound phase $\mathrm{e}^{[18-20]}$. or considering that polymers can have phases with different macromolecular structures (for example, regions heavily crosslinked and regions with light crosslinking) ${ }^{[21,22]}$. Some of these models also include a term considering that stress relaxation can occur due to swelling after water uptake ${ }^{[23,24]}$.

\subsubsection{Jacobs-Jones model}

This model hypothesizes that certain polymers present a two-phase structure, where regions with different crosslinking densities coexist, namely: a heavily crosslinked structure, here named as the dense phase, and a lightly crosslinked structure. For such materials the absorption curve shows two main regions as depicted at Figure 1.

The first stage of the water absorption curve (region I) is characterized by a fast water uptake. This region is associated to diffusion of water at both phases - i.e., at the dense and at the less dense macromolecular structure. At region II, diffusion occurs more slowly, and the water uptake is attributed only to diffusion at the dense phase, since saturation has already occurred at the less crosslinked phase $^{[21]}$. To model the behavior of this two-phase polymer, the equation developed by Jacobs and Jones assumed that diffusion is governed by a Fickian behavior at both phases $^{[21,22]}$. The resultant equation is as follow:

$$
\begin{aligned}
& \frac{M_{\%}}{M_{\infty}}=V_{d}\left\{1-\exp \left[-7.3\left(\frac{D_{d} t}{h^{2}}\right)^{0.75}\right]\right\}+ \\
& \left(1-V_{d}\right)\left\{1-\exp \left[-7.3\left(\frac{D_{l} t}{h^{2}}\right)^{0.75}\right]\right\}
\end{aligned}
$$

where $D_{d}$ and $D_{l}$ are the diffusion coefficients at the dense and at the less dense phase, respectively. $V_{d}$ is the volume fraction associated to the dense phase, and its value depends on both $D_{d}$ and $D_{l}$ values.

The nominal diffusion coefficient, $D_{x}$, can be calculated from the initial slope of the absorption curve $\left(m_{x}\right)$ at region I using the following equation ${ }^{[21]}$ :

$$
D_{x}=\pi\left(\frac{m_{x} h}{4 M_{\infty}}\right)^{2}
$$

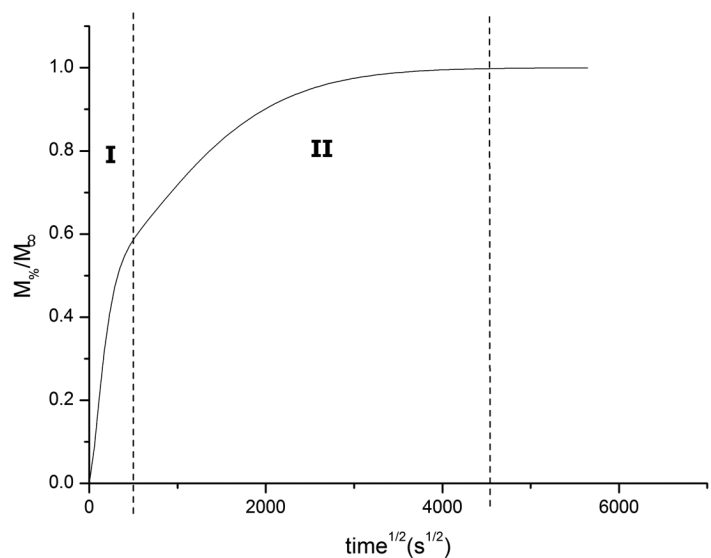

Figure 1. Schematic water absorption curve for resins showing a two phase structure. 


\subsubsection{Modified Jacobs-Jones model}

The modified Jacobs-Jones model ${ }^{[25]}$ considers that the polymer structure consists of a phase where the major amount of water is absorbed (phase 1) and another phase with a different density and/or hydrophilic character (phase 2). The equation of this model is as follow:

$$
\begin{aligned}
& M_{\%}=M_{1}\left\{1-\exp \left[-7.3\left(\frac{D_{1} t}{h^{2}}\right)^{0.75}\right]\right\}+ \\
& M_{2}\left\{1-\exp \left[-7.3\left(\frac{D_{2} t}{h^{2}}\right)^{0.75}\right]\right\}
\end{aligned}
$$

where $D_{1}$ and $D_{2}$ represent the diffusion coefficients of phase 1 and of phase 2 , respectively, and $M_{1}$ and $M_{2}$ are the saturation values of water absorbed at each phase. The maximum absorption value at saturation, $M_{\infty}$, equals $M_{1}+M_{2}$.

Following the same theoretical approach of the Jacobs-Jones model where $D_{2}$ is the diffusion coefficient of the dense phase, here $D$ refers to the diffusion coefficient of the polar, hydrophilic phase whereas $D$ is associated to the less dense phase or to the non-polar phase at the modified model. In both models $D_{2}$ will be an order of magnitude smaller than $D_{1}$, since water diffusion will be hindered by the high crosslinking density or by attraction of water molecules by hydrophilic polar groups ${ }^{[25]}$.

\subsubsection{Berens-Hopfenberg model}

The Berens and Hopfenberg mode ${ }^{[23]}$ includes relaxation effects due to swelling into the diffusion process. This model was successfully used to describe the behavior of polymers as well as composites ${ }^{[16]}$. Its basic equation considers that the amount of absorbed water $\left(M_{0}\right)$ can be represented by adding a term related to Fickian diffusion process $\left(M_{\%, F}\right)$ and a term related to relaxation $\left(M_{\%, R}\right)$, namely:

$$
M_{\%}=M_{\%, F}+M_{\%, R}
$$

The term representing the Fickian diffusion behavior equals Equation 3, namely:

$$
M_{t, F}=M_{\infty, F}\left(1-\exp \left[-7.3\left(\frac{D t}{h^{2}}\right)^{0.75}\right]\right)
$$

where here $M_{\infty, F}$ is the water saturation level disregarding any stress relaxation. The term related to the relaxation effect is given by:

$$
M_{t, R}=M_{\infty, R}\left(1-\exp \left(-k t^{2}\right)\right)
$$

where $k$ is a constant related to the relaxation rate of the material and $M_{\infty, R}$ is the water saturation value related to the relaxation event. This term does not depend on the size of the diffusing molecules, and is only related to stress relief due to swelling caused by water absorption ${ }^{[23]}$. Therefore, water absorption at a time $t$ can be written as:

$$
\begin{aligned}
& M_{\%}=M_{\infty, F}\left(1-\exp \left[-7.3\left(\frac{D t}{h^{2}}\right)^{0.75}\right]\right)+ \\
& M_{\infty, R}\left(1-\exp \left(-k t^{2}\right)\right)
\end{aligned}
$$

\subsubsection{Carter-Kibler model}

Trying to solve problems associated to materials failing to follow the usual Fickian models, Carter and Kibler ${ }^{[18]}$ proposed a model based on two hypothesis, namely: i) the diffusion coefficient does not depend on the water concentration inside the material, and ii) the water molecules coming from the diffusion process itself and/or present at the material can be divided into two phases. This model adds two new parameters, $\alpha$ and $\beta$ These new parameters are related to the probability by unit of time that a water molecule at the free phase transforms into a bound molecule $(\alpha)$ or the probability by unit of time that a bound molecule becomes a free one $(\beta)^{[26]}$.

Taking into account the following boundary condition ${ }^{[19]}$ :

$$
\alpha \ll \frac{D \pi^{2}}{h^{2}} \text { and } \beta \ll \frac{D \pi^{2}}{h^{2}}
$$

It can be written ${ }^{[20]}$ :

$$
M_{\%}=M_{\infty}\left[1-\frac{\beta}{\alpha+\beta} \exp [\alpha t]-\frac{\alpha}{\alpha+\beta} \cdot \frac{8}{\pi^{2}} \exp \left[-\frac{D t}{h^{2}}\right]\right]
$$

\section{Materials and Methods}

The samples were prepared by mixing proper quantities of DGEBA epoxy monomer and TETA hardener, which were weighed within $\pm 0.002 \mathrm{~g}$. These chemicals, from Dow Chemical (Brazil), were used as received, without any further purification. Eight different hardener/resin ratios were prepared, covering the range of epoxy rich to amine rich compositions, and including the stoichiometric one. The different hardener/resin ratios used in this work were labeled according to the amount of hardener per hundred parts of resin, in weight, denoted henceforth as phr. The ratios used are referred to in Tables 1-3, and phr 13 corresponds to the stoichiometric composition.

The samples were cast in plate-shaped open silicone molds, with dimensions appropriate to water absorption measurements ( $n=25 \mathrm{~mm}, l=105 \mathrm{~mm}$ and $h=4 \mathrm{~mm}$ ), and were cured at room temperature, $25 \pm 3{ }^{\circ} \mathrm{C}$. The samples obtained were dried to constant weight at $60^{\circ} \mathrm{C}$ and were, then, soaked in distilled water. Care was taken in order to avoid contact of the specimens with the walls of the containers. Therefore, all surfaces of the specimens were in close contact with the soaking medium.

The weight gain $v s$. time of immersion curve was obtained following the procedures described by the ASTM D570 standard for plastics. The experimental data obtained were modeled using the theoretical models described at Section 2.

\section{Experimental Results and Discussion}

The results obtained by fitting the models described in item 2 to the experimental points are listed in Tables 1-3. Table 1 shows the fitted values using the Fickian models described in item 2.1. Tables 2, 3 are devoted to list the adjusted values when a non-Fickian behavior was used, item 2.2. The fitted curves were obtained using non-linear regression, and the least squares method to obtain the best 
Table 1. Fickian models - Equations 3 and 5.

\begin{tabular}{|c|c|c|c|c|c|c|}
\hline \multirow[b]{2}{*}{ PHR } & \multicolumn{3}{|c|}{ Fick Model } & \multicolumn{3}{|c|}{ McKague Model } \\
\hline & $\mathbf{M} \infty(\%)$ & $\begin{array}{l}\mathrm{D} \times 10^{-7} \\
\left(\mathrm{~mm}^{2} / \mathrm{s}\right)\end{array}$ & $\mathbf{r}^{2}$ & $\mathbf{M} \infty(\%)$ & $\begin{array}{l}\mathrm{D} \times 10^{-7} \\
\left(\mathrm{~mm}^{2} / \mathrm{s}\right)\end{array}$ & $\mathbf{r}^{2}$ \\
\hline 7 & 2.78 & 3.94 & 0.90 & 3.08 & 4.07 & 0.95 \\
\hline 9 & 3.41 & 2.46 & 0.93 & 4.16 & 1.92 & 0.97 \\
\hline 11 & 3.39 & 3.52 & 0.92 & 4.33 & 3.46 & 0.96 \\
\hline 13 & 4.01 & 2.61 & 0.93 & 4.81 & 2.29 & 0.97 \\
\hline 15 & 5.11 & 1.67 & 0.92 & 7.18 & 0.94 & 0.97 \\
\hline 17 & 5.26 & 2.02 & 0.91 & 6.82 & 1.36 & 0.96 \\
\hline 19 & 5.83 & 2.01 & 0.93 & 7.41 & 1.43 & 0.97 \\
\hline 21 & 6.56 & 1.70 & 0.94 & 9.01 & 1.01 & 0.98 \\
\hline
\end{tabular}

Table 2. Non-Fickian models - Equations 6 and 8.

\begin{tabular}{|c|c|c|c|c|c|c|c|c|c|c|c|c|}
\hline \multirow[b]{2}{*}{ PHR } & \multicolumn{6}{|c|}{ Jacobs-Jones Model } & \multicolumn{6}{|c|}{ Modified Jacobs-Jones Model } \\
\hline & $\mathbf{M} \infty(\%)$ & $\mathbf{V}_{\mathrm{d}}$ & $\begin{array}{l}\mathrm{D} \times 10^{-7} \\
\left(\mathrm{~mm}^{2} / \mathrm{s}\right)\end{array}$ & $\begin{array}{l}D_{d} \times 10^{-8} \\
\left(\mathrm{~mm}^{2} / \mathrm{s}\right)\end{array}$ & $\begin{array}{l}\mathrm{D}_{1} \times 10^{-5} \\
\left(\mathrm{~mm}^{2} / \mathrm{s}\right)\end{array}$ & $\mathbf{r}^{2}$ & $\begin{array}{l}\mathrm{M}_{1} \\
(\%)\end{array}$ & $\begin{array}{c}M_{2} \\
(\%)\end{array}$ & $\begin{array}{l}\mathbf{M} \infty \\
(\%)\end{array}$ & $\begin{array}{l}\mathrm{D}_{1} \times 10^{-7} \\
\left(\mathrm{~mm}^{2} / \mathrm{s}\right)\end{array}$ & $\begin{array}{c}D_{2} \times 10^{-9} \\
\left(\mathrm{~mm}^{2} / \mathrm{s}\right)\end{array}$ & $\mathbf{r}^{2}$ \\
\hline 7 & 5.05 & 0.8 & 2.39 & 3.03 & 0.50 & 0.98 & 0.98 & 3.57 & 4.55 & 0.53 & 39.60 & 0.98 \\
\hline 9 & 4.97 & 0.8 & 1.28 & 4.54 & 0.27 & 0.98 & 1.00 & 10.49 & 11.49 & 0.32 & 9.20 & 0.98 \\
\hline 11 & 6.37 & 0.8 & 0.90 & 2.65 & 0.26 & 0.97 & 1.45 & 16.03 & 17.48 & 0.21 & 3.90 & 0.97 \\
\hline 13 & 4.82 & 0.9 & 2.17 & 12.24 & 18.08 & 0.98 & 0.69 & 4.40 & 5.10 & 7.57 & 92.00 & 0.98 \\
\hline 15 & 7.74 & 0.9 & 0.98 & 4.23 & 6.09 & 0.99 & 0.77 & 7.82 & 8.60 & 6.16 & 34.29 & 0.98 \\
\hline 17 & 12.04 & 0.9 & 0.49 & 1.82 & 0.59 & 0.98 & 1.40 & 124.10 & 125.50 & 0.41 & 0.51 & 0.98 \\
\hline 19 & 8.13 & 0.9 & 0.81 & 6.05 & 13.23 & 0.99 & 0.86 & 7.02 & 7.88 & 11.36 & 63.61 & 0.99 \\
\hline 21 & 8.91 & 0.9 & 0.83 & 5.66 & 10.01 & 0.99 & 0.86 & 8.35 & 9.21 & 11.10 & 53.31 & 0.99 \\
\hline
\end{tabular}

Table 3. Non-Fickian models - Equation 12.

\begin{tabular}{|c|c|c|c|c|c|c|}
\hline \multirow{2}{*}{ PHR } & \multicolumn{5}{|c|}{ Berens and Hopfenberg Model } & \multirow{2}{*}{$\mathbf{r}^{2}$} \\
\hline & $\mathbf{M} \infty,_{F}(\%)$ & $M \infty,_{R}(\%)$ & $M \infty *(\%)$ & $\mathrm{k} \times 10^{-12}\left(\mathrm{~s}^{-2}\right)$ & $\mathrm{D} \times 10^{-7}\left(\mathrm{~mm}^{2} / \mathrm{s}\right)$ & \\
\hline 7 & 2.47 & 0.60 & 3.07 & 5.69 & 1.64 & 0.96 \\
\hline 9 & 3.01 & 0.53 & 3.54 & 1.06 & 1.52 & 0.95 \\
\hline 11 & 3.06 & 0.74 & 3.80 & 1.18 & 1.49 & 0.96 \\
\hline 13 & 3.81 & 0.90 & 4.71 & 0.29 & 1.13 & 0.96 \\
\hline 15 & 4.49 & 0.87 & 5.37 & 0.11 & 1.11 & 0.95 \\
\hline 17 & 4.79 & 0.92 & 5.71 & 0.24 & 1.09 & 0.94 \\
\hline 19 & 5.27 & 1.00 & 6.27 & 0.20 & 1.15 & 0.96 \\
\hline 21 & 5.56 & 1.25 & 6.81 & 0.12 & 1.10 & 0.96 \\
\hline
\end{tabular}

$* M_{\infty}=M_{\infty, F}+M_{\infty, R}^{[24]}$.

fit between the experimental data points and the theoretical equations.

All models except the one from Carter and Kibler ${ }^{[18]}$ could be fitted to the experimental results. The lack of consistence of the Carter and Kibler model can be explained regarding that the boundary conditions stablished by Equation 13 were not satisfied - i.e., the values obtained to both $\alpha$ and $\beta$ are greater than $\frac{D \pi^{2}}{h^{2}}$. Therefore, the results obtained when this model was applied are not included at the present topic.

The values of $V_{d}$ listed at Table 2 (Jacob-Jones model) were obtained taking into account the best correlation coefficient between the experimental points and the fitted theoretical curve when $V_{d}$ was varied between its boundary values - from 0 to 1 - at steps of 0.1 . This procedure was used because $V_{d}$ depends on the values of both $D_{d}$ and $D_{l}$, and, therefore, its value is a necessary condition to apply Equation 6.
To verify the results listed at Table 2 for $V_{d}$, the graphical methodology described at the work of Jacobs and Jones ${ }^{[21,22]}$ was also used. The complete description of the graphical approach can be found at the works of Jacobs and Jones ${ }^{[21,22]}$, and is not reproduced here for the sake of shortness.

As presented on several papers water absorption and diffusion on polymers are related to different factors, but are mainly affected by the free volume existent at the macromolecular structure and by the affinity of the specific polymer to water ${ }^{[17,27]}$.

The amount of free volume is considered as the main driving force to water absorption, and is related to several different physical characteristics of the polymer ${ }^{[15,16,28-31]}$. These physical characteristics are intimately linked to the degree of cure, the stoichiometric ratio and with the stiffness of the molecular bonds ${ }^{[29-31]}$. The chemical affinity of a polymer to water, by the other side, is attributed to the 
polymer polarity -i.e., to the presence of sites with hydrogen bonds along the polymeric chain ${ }^{[26]}$.

From the experimental results, in general, it is observed that higher values of $M_{\infty}$ were obtained with the increase of the hardener ratio. In fact, in a previous work Soles and $\mathrm{Yee}^{[31]}$ found that the increase of the amine ratio resulted on an increase of the amount of absorbed water. The increase of the water up-take was attributed to the increase of the free volume of the epoxy system, what eases the water diffusion path and increases the number of sites to be occupied by water molecules ${ }^{[29]}$. Carfagna et al. ${ }^{[32]}$, using differential scanning calorimetry, has observed also that if a large excess of hardener is used high levels of water uptake are observed, and this behavior can be linked to the formation of microcavities within the matrix in an exothermic process.

While the amount of water increased with the increase of the amount of hardener, diffusivity $(D)$ showed little variation or decreased with the increase of the hardener content. Since the values of $M_{\infty}$ are primarely governed by an increase on the free volume of the polymer, the decrease of the diffusivity can be explained by the increase on the polarity of the system and by topological changes on the chains ${ }^{[16,29]}$. The increase in free volume promotes growth in the number of nanovoids throughout the network, which in turn act as routes of access of water molecules to the interaction sites. This will slow molecular motion due to water affinity to hydroxyl $(-\mathrm{OH})$ groups present along the chain, slowing the diffusion process ${ }^{[28,29]}$.

Comparing the results obtained between Fickian and non-Fickian models, Tables 1-3, it is verified that the latter have a best fit to the experimental data for all tested proportions of hardener. In fact, the determination coefficient values $\left(r^{2}\right)$ for non-Fickian models were very close to 1 , denoting very high correlation between the curve stipulated by the models and the experimental data. It is worth saying that the McKague model ${ }^{[13]}$ also presented high correlation with experimental results. However, it is only a mathematical modification of the Fick's approach, without including any new physical approach to the diffusion problem.
Based on this fitting, it can be said that for all tested hardener/epoxy ratios a macromolecular structure with two phases was formed. Namely, a dense phase with a large number of crosslinks and a less dense phase with fewer crosslinks, as predicted by the models of Jacobs and Jones $^{[21,22]}$. For all formulations tested, the proportion of the dense phase present in the system was superior to that of the "less" dense phase, what is depicted by the high volume fraction obtained for the dense phase $\left(V_{d}\right)$.

The variation found in the proportion of the dense phase is closely related to the topology of the chains along the material. The different ways the crosslinking reactions can occur due to the variation of the hardener to epoxy monomer ratio can lead to the formation of a more open structure, contributing to the diffusion of small molecules such as water, or a more compact structure, acting as barriers to the movement of molecules ${ }^{[29]}$. For the epoxy rich systems (phr 7, 9 and 11) the formation of a more open structure is likely, because after depletion of amine groups, secondary reactions such as homopolimerization and ether formation can occur ${ }^{[4,9]}$. This structure will favor higher diffusion rates $(D)$ and will have smaller proportion of dense phase $\left(V_{d}\right)$. Amine rich systems, by contrary, have a more closed structure, since excess of amine hardener in these systems will promote opening of all available epoxy rings, and will result on a highly crosslinked structure, leading to a decrease in diffusivity $(D)$ and an increase in the volume fraction of the dense phase $\left(V_{d}\right)$.

The curves obtained by applying the Jacobs-Jones models, Table 2, showed high convergence for all tested hardener to epoxy ratios. Examples of the curve fitting to the experimental points are shown in Figure 2. In some cases, however, the values for $M_{\infty}$ diverged and showed inconsistent results. This behavior was particularly observed for the phr 17 ratio at the Jacobs-Jones model and for phr 9, 11 and 17 ratios at the modified Jacobs-Jones model (Figure 3). The results obtained were associated to the fact that the experimental curves showed a steady increase of the amount of water, without a clear plateau indicating

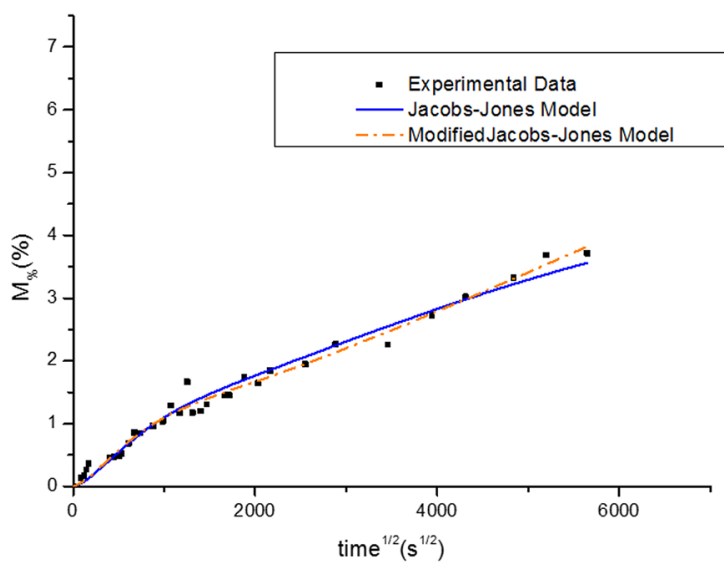

(a)

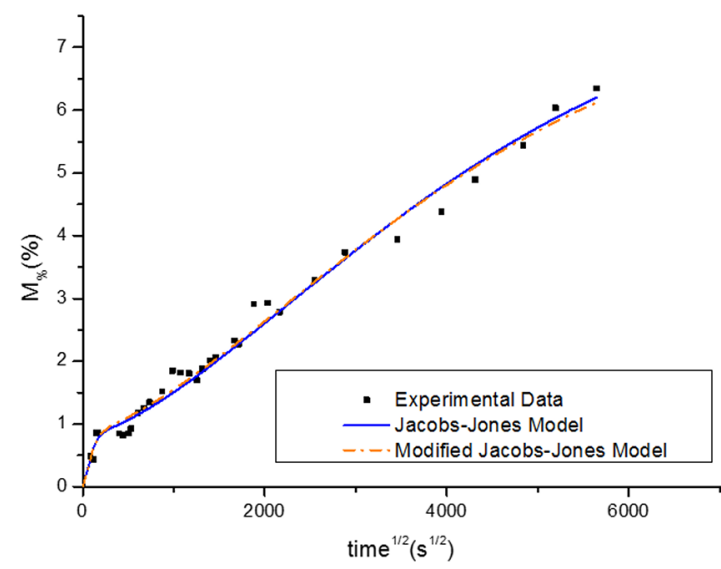

(b)

Figure 2. Fitting of the experimental points to the Jacobs-Jones models. Characteristic curves for (a) phr 7, 9 and 11 (b) phr 13, 15, 17, 19 and 21. 


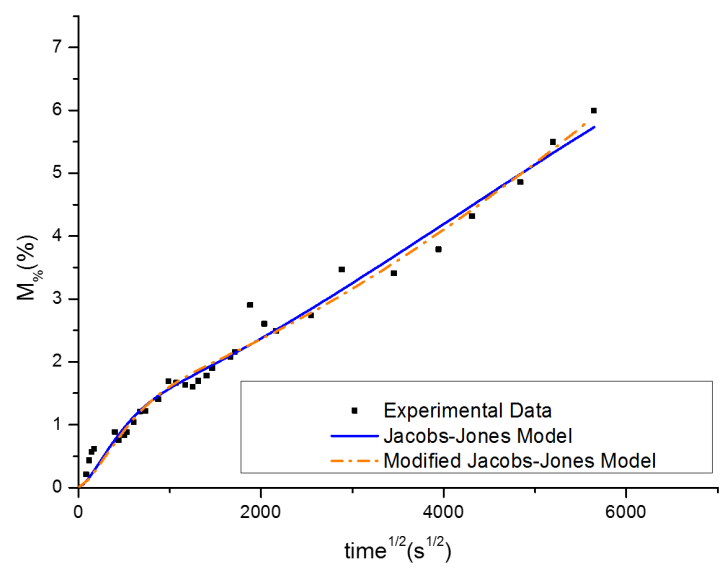

Figure 3. Characteristic curve exhibited by phr 17 for Jacobs-Model, and phr 9, 11 and 17 for modified Jacobs-Jones model showing an abnormal behavior.

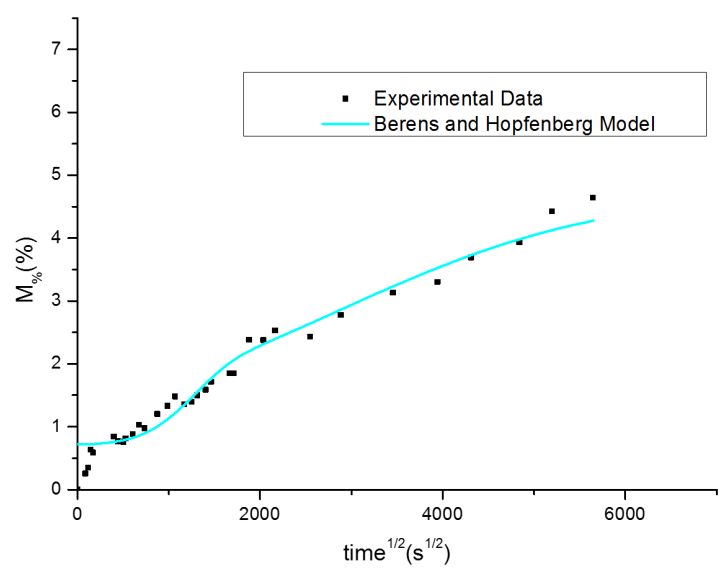

Figure 4. Characteristic curve obtained by applying the Berens-Hopfenberg model to the experimental mass gain vs. time data points.

saturation $^{[3]]}$. This abnormal behavior is related to polymer degradation caused by water absorption ${ }^{[15,33]}$.

The degradation occurs by formation of hydrogen bonds between the water molecules and polar groups present in the polymer chain, causing rupture of the initial network ${ }^{[15]}$. The water absorption not only causes plasticization of the resin, but also causes a change in the stress state, what favors the formation of cracks by swelling. These phenomena contribute to an increase in the variation of the internal structure of the material and cause an increasing weight gain $\left(M_{\%}\right)$ close to the equilibrium level, so that this level is never achieved ${ }^{[33]}$.

The curves obtained with the Berens-Hopfenberg model, Table 3, showed similar results for all phr ratios, with little variation in the diffusivity $(D)$ values and continued increase of the saturation values related to Fickian diffusion $\left(M_{\infty, F}\right)$ and also due to polymer swelling $\left(M_{\infty, R}\right)$. The final behavior was similar to the one obtained with the Jacobs-Jones models (Table 2).
The good fit of the Berens-Hopfenberg model to the experimental points does not exclude the approach and discussion thus far made based on the results found by the Jacobs-Jones model, but rather complements and confirms the behavior of both $D$ and $M_{\infty}$, using, however, the concept of stress relaxation. Clearly, it can be seen that the characteristic curve obtained for the different hardener ratios (Figure 4) can be divided into two regions: an initial absorption, following an almost Fickian behavior and a subsequent absorption with slower rates of weight gain. The second region reflects the changes that occur in the matrix resin as result of the stress relaxation ${ }^{[30]}$.

Water molecules are generally linked to hydroxyl groups $(\mathrm{OH})$ formed during the process of opening of the epoxy ring, contributing to swelling of the material and consequently to the relaxation process. Water molecules are divided into two phases: one phase bound to the polymer chain and a free phase occupying the empty spaces present within the structure of the material ${ }^{[17]}$. The higher the proportion of free phase in relation to the bonded phase, the greater the mass gain at equilibrium, since a large number of water molecules will be "loose" to fill an increased amount of free spaces.

Based on the results obtained by applying the Berens-Hopfenberg model, it can be seen that the greater the amount of amine in the epoxy system, the greater the proportion of free phase is, since the free volume is proportional to the amount of hardener in the system, as observed by Soles and co-workers ${ }^{[2,31]}$, Grave and co-workers ${ }^{[30]}$, and Carfagna and co-workers ${ }^{[32]}$.

\section{Conclusions}

The use of different diffusion models allowed characterizing the absorption behavior of the DGEBA/TETA system with different hardener/epoxy ratios. The models used showed excellent convergence, with the exception of the Carter and Kibler model.

Weight gain due to water absorption increased with increasing the hardener content, while diffusivity followed the opposite behavior. The trend observed for these two parameters could be explained by the increase of the free volume within the material, and by interactions caused by chain polarity and topology.

The behavior observed for all systems, i.e., for all hardener/epoxy monomer ratios, followed a non-Fickian trend. The best fit was obtained when the Jacobs-Jones models were used, characterizing the presence of two phases in the material. The denser phase, i.e., the one with a higher crosslink density, is present in major proportion, and a less dense phase, with a lesser number of crosslinks is present in a smaller proportion.

For some formulations, especially the one with phr 17 when the Jacobs-Jones model was used, or the ones with phr 9, 11 and 17 when the modified Jacobs-Jones model is used, the data points evidenced the occurrence of degradation due to water absorption.

\section{Acknowledgements}

The authors acknowledge the grants from the Brazilian funding agency CNPq. 


\section{References}

1. Lee, H., \& Neville, K. (1982). Handbook of epoxy resins. New York: McGraw-Hill.

2. Groß, A., Kollek, H., Schormann, A., \& Brockmann, H. (1988). Spectroscopical contributions to the regioselectivity of nucleophilic curing reactions in epoxy resins. International Journal of Adhesion and Adhesives, 8(3), 147-158. http://dx.doi. org/10.1016/0143-7496(88)90093-0.

3. Jiang, S., Zha, S., Xia, L., \& Guan, R. (2015). Synthesis and characterization of diphenylsilanediol modified epoxy resin and curing agent. Journal of Adhesion Science and Technology, 29(7), 641-656. http://dx.doi.org/10.1080/01694243.2014.10 03177.

4. Morgan, R. J., \& Mones, E. T. (1987). The cure reactions, network structure, and mechanical response of diaminodiphenyl sulfone-cured tetraglycidyl 4,4'diaminodiphenyl methane epoxies. Journal of Applied Polymer Science, 33(4), 999-1020. http://dx.doi.org/10.1002/app.1987.070330401.

5. Thomas, R., Yumei, D., Yuelong, H., Le, Y., Moldenaers, P., Weimin, Y., Czigany, T., \& Thomas, S. (2008). Miscibility, morphology, thermal, and mechanical properties of a DGEBA based epoxy resin toughened with a liquid rubber. Polymer, 49(1), 278-294. http://dx.doi.org/10.1016/j.polymer.2007.11.030.

6. d'Almeida, J. R. M., \& Monteiro, S. N. (1996). Analysis of the fracture surface morphology of an epoxy system as a function of the resin/hardener ratio. Journal of Materials Science Letters, 15, 955-958. http://dx.doi.org/10.1007/BF00241436.

7. d'Almeida, J. R. M., \& Monteiro, S. N. (1998). The influence of the amount of hardener on the tensile mechanical behavior of an epoxy system. Polymers for Advanced Technologies, 9(3), 216-221. http://dx.doi.org/10.1002/(SICI)10991581(199803)9:3<216::AID-PAT746>3.0.CO;2-S.

8. d'Almeida, J. R. M., Cella, N., Monteiro, S. N., \& Miranda, L. C. M. (1998). Thermal diffusivity of an epoxy system as a function of the hardener content. Journal of Applied Polymer Science, 69(7), 1335-1341. http://dx.doi.org/10.1002/(SICI)10974628(19980815)69:7<1335::AID-APP8>3.0.CO;2-F.

9. Chiao, L., \& Lyon, R. E. (1990). A fundamental approach to resin cure kinectics. Journal of Composite Materials, 24(7), 739-752. http://dx.doi.org/10.1177/002199839002400704.

10. Bouchonneau, N., Carvalho, A. R., Macêdo, A. R. L., Viana, L. U., Nascimento, A. P., Duarte, J. B. F., \& Macêdo, A. R. M. (2010). Análise da absorção de água em dois polímeros expandidos: desenvolvimento do módulo de flutuabilidade de um mini-robô submarino. Polímeros: Ciência e Tecnologia, 20(3), 181-187. http://dx.doi.org/10.1590/S0104-14282010005000032.

11. Crank, J. (1975). The mathematics of diffusion (2nd ed). Oxford: Clarendon Press.

12. Shen, C. H., \& Springer, G. S. (1976). Moisture absorption and desorption of composite materials. Journal of Composite Materials, 2(1), 2-20. http://dx.doi.org/10.1177/002199837601000101.

13. McKague, E. L., Reynolds, J. D., \& Halkias, J. E. (1976). Moisture Diffusion in Fiber Reinforced Plastics. Journal of Engineering Materials and Technology, 98(1), 92-95. http:// dx.doi.org/10.1115/1.3443342.

14. Bortolin, A., Aouada, F. A., Longo, E., \& Mattoso, L. H. C. (2012). Investigação do processo de absorção de água de hidrogéis de polissacarídeo: efeito da carga iônica, presença de sais, concentrações de monômero e polissacarídeo. Polímeros: Ciência e Tecnologia, 22(4), 311-317. http://dx.doi.org/10.1590/ S0104-14282012005000046.

15. Papanicolaou, G. C., Kosmidou, Th. V., Vatalis, A. S., \& Delides, C. G. (2006). Water absorption mechanism and some anomalous effects on the mechanical and viscoelastic behavior of an epoxy system. Journal of Applied Polymer Science, 99(4), 1328-1339. http://dx.doi.org/10.1002/app.22095.

16. Manfredi, L. B., Santis, H., \& Vásquez, A. (2008). Influence of the addition of montmorillonite to the matrix of unidirectional glass fibre/epoxy composites on their mechanical and water absorption. Composites Part A: Applied Science and Manufacturing, 39(11), 1726-1731. http://dx.doi.org/10.1016/j. compositesa.2008.07.016.

17. Ahmad, Z., Ansell, M. P., \& Smedley, D. (2011). Moisture absorption characteristics of epoxy based adhesive reinforced with CTBN and ceramic particles for bonded-in timber connection: Fickian or Non-Fickian behavior. IOP Conference Series. Materials Science and Engineering, 17, 012011. http:// dx.doi.org/10.1088/1757-899X/17/1/012011.

18. Carter, H. G., \& Kibler, K. G. (1978). Langmuir-Type model for anomalous moisture diffusion in composite resins. Journal of Composite Materials, 12(2), 118-131. http://dx.doi. org/10.1177/002199837801200201.

19. Bonniau, P., \& Bunsell, A. R. (1981). A comparative study of water absorption theories applied to glass epoxy composites. Journal of Composite Materials, 15(3), 272-293. http://dx.doi. org/10.1177/002199838101500306.

20. Bonniau, P., \& Bunsell, A. R. (1981). Water absorption by glass fibre reinforced epoxy resin. In I. H. Marshall (Ed.), Composite structures (pp. 92-105). Amsterdam: Springer. http://dx.doi. org/10.1007/978-94-009-8120-1_7.

21. Jacobs, P. M., \& Jones, F. R. (1989). Diffusion of moisture into two-phase polymers. Journal of Materials Science, 24(7), 2331-2336. http://dx.doi.org/10.1007/BF01174492.

22. Jacobs, P. M., \& Jones, F. R. (1989). Diffusion of moisture into two-phase polymers. Journal of Materials Science, 24(7), 2343-2347. http://dx.doi.org/10.1007/BF01174494.

23. Berens, A. R., \& Hopfenberg, H. B. (1978). Diffusion and relaxation in glassy polymer powders: 2 . Separation of diffusion and relaxation parameters. Polymer, 19(5), 489-496. http:// dx.doi.org/10.1016/0032-3861(78)90269-0.

24. Pritchard, G., \& Speake, S. D. (1987). The use of water absorption kinetic data to predict laminate property changes. Composites, 18(3), 227-232. http://dx.doi.org/10.1016/00104361(87)90412-5.

25. Maggana, C., \& Pissis, P. (1999). Water sorption and diffusion studies in na epoxy resin system. Journal of Polymer Science Part B, 37(11), 1165-1182. http://dx.doi.org/10.1002/(SICI)10990488(19990601)37:11<1165::AID-POLB11>3.0.CO;2-E.

26. Popineau, S., Rondeau-Mouro, C., Sulpice-Gaillet, C., \& Shanahan, M. E. R. (2005). Free/bound water absorption in an epoxy adhesive. Polymer, 46(24), 10733-10740. http:// dx.doi.org/10.1016/j.polymer.2005.09.008.

27. Abdelkader, A. F., \& White, J. R. (2005). Water absorption in epoxy resins: The effects of the crosslinking agent and curing temperature. Journal of Applied Polymer Science, 98(6), 25442549. http://dx.doi.org/10.1002/app.22400.

28. Soles, C. L., Chang, F. T., Gidley, D. W., \& Yee, A. F. (2000). Contributions of the nanovoid structure to the kinectics of moisture transport in epoxy resins. Journal of Polymer Science Part B, 38(5), 776-791. http://dx.doi.org/10.1002/(SICI)10990488(20000301)38:5<776::AID-POLB15>3.0.CO;2-A.

29. Soles, C. L., Chang, F. T., Bolan, B. A., Hristov, H. A., Gidley, D. W., \& Yee, A. F. (1998). Contributions of the nanovoid structure to the moisture absorption properties of epoxy resins. Journal of Polymer Science Part B, 36(17), 3035-3048. http:// dx.doi.org/10.1002/(SICI)1099-0488(199812)36:17<3035::AIDPOLB4>3.0.CO;2-Y.

30. Grave, C., Mcewan, I., \& Pethrick, R. A. (1998). Influence of stoichiometric ratio on water absorption in epoxy resins. Journal of Applied Polymer Science, 69(12), 2369-2376. http://dx.doi. 
org/10.1002/(SICI)1097-4628(19980919)69:12<2369::AIDAPP8>3.0.CO;2-6.

31. Soles, C. L., \& Yee, A. F. (2000). A discussion of the molecular mechanisms of moisture transport in epoxy resins. Journal of Polymer Science Part B, 38(5), 792-802. http://dx.doi. org/10.1002/(SICI)1099-0488(20000301)38:5<792::AIDPOLB16>3.0.CO;2-H.

32. Carfagna, C., Apicella, A., \& Nicolais, L. (1982). The effect of the prepolymer composition of amino-hardened epoxy resins on the water sorption behavior and plasticization. Journal of Applied Polymer Science, 27(1), 105-112. http://dx.doi. org/10.1002/app.1982.070270112.

33. Hahn, H. T. (1987). Hygrothermal damage in graphite/epoxy laminates. Journal of Engineering Materials and Technology, 109(1), 3-11. http://dx.doi.org/10.1115/1.3225930.

Received: Mar: 06, 2015

Revised: Aug. 15, 2015

Accepted: Aug. 31, 2015 